\title{
DAMPAK IMPLEMENTASI ZAKAT PRODUKTIF
}

\author{
Muh. Ruslan Abdullah \\ Fakultas Syariah Institut Agama Islam Negeri (IAIN) Palopo \\ Email : muh_ruslan_abdullah@iainpalopo.ac.id
}

\begin{abstract}
Zakat is the third pillar of Islam that is considered to have a significant role in overcoming various economic problems, problems-problems are: 1. Unemployment, 2. Poverty, 3. Load the crisis and accounts payable, 4. The economy is bad, 5. Hoarding possessions. productive zakat is implemented in the form of venture capital assistance, resource assistance effort so that people can rise from the economic downturn. Distribution of zakat productively contributes greatly to the economy of poor community.
\end{abstract}

Keywords : Productive Zakat, Muzakki, Mustahik, empowering, Distribution

\begin{abstract}
Abstrak
Zakat adalah pilar ketiga Islam yang dianggap memiliki peran signifikan dalam mengatasi berbagai masalah ekonomi, masalah-masalah adalah: 1. Pengangguran, 2. Kemiskinan, 3. Muat krisis dan hutang, 4. Ekonomi buruk, 5. Menimbun harta. Zakat produktif dilaksanakan dalam bentuk bantuan modal ventura, upaya bantuan sumber daya sehingga orang dapat bangkit dari krisis ekonomi. Distribusi zakat secara produktif berkontribusi besar pada perekonomian masyarakat miskin.

Kata Kunci; Zakat Produktif, Muzakki, Mustahik, Pemberdayaan, Distribusi
\end{abstract}

\section{PENDAHULUAN}

Arah dan tujuan pembangunan menurut konsep Islam adalah gerakan untuk meningkatkan kesejahteraan dan kehormatan masyarakat, dengan meningkatkan kemam-puan intelektual kerja dan pengabdiannya, untuk menegakkan misi kekhalifaan serta khairaummah. Untuk itulah maka konsep Islam meletakkan dasar pada aspek manusia dengan konsentrasi akhlak.

Aspek keadilan yang diukur dengan tingkat kesejahteraan dewasa ini, hanya mengandalkan peran pemerintah dalam melakukan pemerataan melalui pajak dan pemberian pelayanan umum (sosial eko-nomi), hasil akhir yang dicapai tetap memperlihatkan adanya ketimpangan yang makin tajam, antara si kaya dan si miskin. Ketim-pangan ini di sebabkan karena moral, dan hukum ekonomi tidak mengandung muatan hakiki keadilan (keridhaan, manfaat dan kejelasan). ${ }^{1}$

\footnotetext{
.1 Abdurahman A. Basalamah, Ekonomi Bulan sabit, Gerakan Pembagunan Dalam Konsep Islam (Ujung Pandang; PT. Umitoha Ukhuwah Grafika, 1996), h. 4
} 
Islam menghendaki kesejahteraan secara menyeluruh Individu, keluarga, masyarakat dan bangsa, terpadu antara rohaniah dan jasmaniah. Hal ini tergambar dari perintah Allah Swt., dalam Al-Qur'an; perintah berkorban dan shalat, serta perintah Zakat. Jelas terdapat keterpaduan antara aspek ekonomi dan sosial. ${ }^{2}$ Dalam QS. AlHasyir: 7 dijelaskan

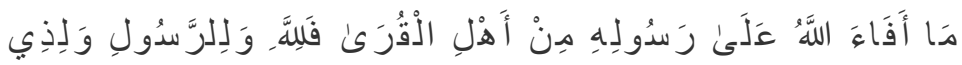

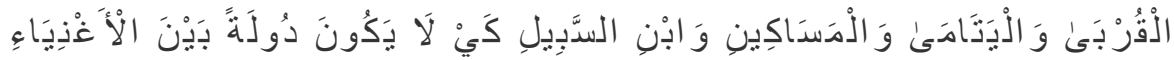

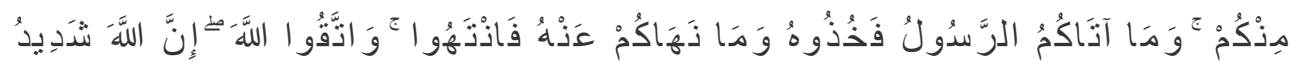

$$
\begin{aligned}
& \text { الُْعِقَاب }
\end{aligned}
$$

Terjemahan :

...Supaya harta itu jangan beredar di antara orang-orang Kaya saja di antara kamu. apa yang diberikan Rasul kepadamu, Maka terimalah. dan apa yang dilarangnya bagimu, Maka tinggalkanlah dan bertakwalah kepada Allah. Sesungguhnya Allah Amat keras hukumannya.

Dari ayat di atas menjelaskan bahwa harta tidak terputar di antara orang-orang kaya saja. Kata dulah, dalam bahasa Arab, sebutan untuk benda yang diputar oleh suatu kaum. Kata tersebut juga berarti nama untuk harta yang diputar. Jadi harta yang merupakan hak yang harus diberikan kepada fakir miskin supaya bisa menjadi modal hidup meraka, dan tidak hanya berputar di tangan orang kaya saja. ${ }^{3}$

Islam mengajarkan untuk peka ter-hadap segala sesuatu yang terjadi di sekeliling kita. Islam pun menetapkan cara agar harta kekayaan dapat terdistribusikan dengan baik disetiap kalangan umatnya. Islam menghendaki kesejahteraan secara menyeluruh Individu, keluarga, masyarakat dan bangsa, terpadu antara rohaniah dan jasmaniah. Hal

\footnotetext{
2 Ibid,h. 23

3 Taqyuddin An-Nabhani. Membangun Sistem Ekonomi Alternatif Perspektif Islam (Surabaya; Risala Gusti, 1996) h. 274
} 
ini tergambar dari perintah Allah Swt., dalam Al-Qur'an; perintah berkorban dan shalat, serta perintah Zakat. Jelas terdapat keterpaduan antara aspek ekonomi dan sosial. ${ }^{4}$

Islam bukanlah agama yang mem-biarkan segala permasalahan ini hadir tanpa batas. Namun Islam pun tumbuh dengan banyak kepedulian positif terhadap realitas permasalahan, seperti fenomena perekono-mian. Zakat yang merupakan rukun Islam ketiga yang dianggap mempunyai peran yang signifikan dalam mengatasi berbagai permasalahan ekonomi, permasalahan ter-sebut yaitu: 1. Pengangguran, 2. Kemiskinan, 3. Beban krisis dan hutang piutang, 4. Perekonomian buruk, 5. Penimbunan harta.5 Zakat saat ini, diharapkan mampu meng-angkat taraf hidup umat muslim dan menyelesaikan permasalah financial umat muslim yang berada di bawah garis kemiskinan serta mampu mendidik umat muslim, menjadi muslim yang unggul. Salah satu sektor yang sangat menarik dikaji dalam ekonomi Islam adalah sektor yang berkaitan dengan tanggung jawab pemerintah muslim di bidang keuangan dan perekonomian, tanggung jawab pemerintah di bidang ekonomi dapat di bagi menjadi dua bagian :

1) Tanggung jawab untuk memenuhi kebutuhan kaum fakir miskin 2) Tanggung jawab untuk memberikan petunjuk atau bimbingan di berbagai sektor produksi dan distribusi. $^{6}$

\section{KONSEPSI ZAKAT}

Secara bahasa zakat kata dasar (masdar)-nya zaka yang berarti berkah, tumbuh, bersih, baik, dan bertambah. Bagi orang yang mengeluarkan zakat, hati dan jiwanya akan bersih, sebagaimana firman Allah Swt dalam surah at-Taubah ayat 103, selain hati dan jiwanya bersih, kekayaannya akan bersih pula. Dari ayat ini tergambar bahwa zakat yang dikeluarkan oleh para muzaki akan dapat membersihkan dan menyucikan

\footnotetext{
${ }^{4}$ Abdurahman A. Basalamah, Ekonomi Bulan sabit, Gerakan Pembagunan Dalam Konsep Islam (Ujung Pandang; PT. Umitoha Ukhuwah Grafika, 1996), h. 1 Ibid,- 23

${ }^{5}$ Yusuf Qaradhawi, Spektrum Zakat Dalam Membangun Ekonomi Rakyat .Terjemahan dari judul Dauru Al-Zakat, fi'Iiaaj al-Musykilaat al-Iqtisshaadiyah (Jakarta; Zikrul Hakim, 2005), h. 2

${ }^{6}$ Muhammad Husaini Bahesyti dan Jawad Bahonar, Intisari Islam Kajian Komprehensif tentang Hikmah Ajaran Islam. Cet. 1 (Jakarta; Lentera, 2003), h. 433
} 
hati manusia, tidak lagi mempunyai sifat yang tercela terhadap harta, seperti rakus dan kikir. $^{7}$

Sedangkan menurut terminologi Syari'ah, Zakat adalah mengeluarkan sebagian harta, diberikan kepada yang berhak menerimnya, sehingga harta yang tinggal menjadi bersih dan orang yang mempunyai harta menjadi suci jiwa dan tingka lakunya. Namun lain bagi zakat itu ialah sedekah yang dibagi kepada sedekah wajib disebut zakat, dan sedekah sunnat. Membayar zakat termasuk rukun Islam, dalam Al-Qur'an kalimat shalat sering dihubungkan dengan zakat. Antara keduanya mempunyai gubungan yang erat dalam membina orang beriman. Wajib zakat bergantung pula kepada nisab dan haul, nisab adalah harta itu telah sampai kepada jumlah yang telah ditentukan dan haul adalah harta itu telah sampai satu tahun. ${ }^{8}$

\section{Dasar Hukum Zakat}

QS.Al-Taubah; (9): 103

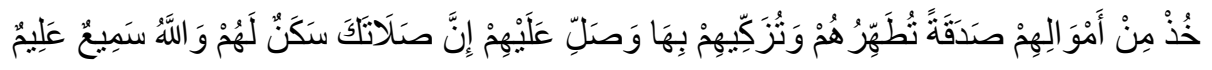

Terjemahnya;

Ambillah zakat dari sebagian harta mereka, dengan zakat itu kamu membersihkan[658] dan mensucikan [659] mereka dan mendoalah untuk mereka. Sesungguhnya doa kamu itu (menjadi) ketenteraman jiwa bagi mereka. dan Allah Maha mendengar lagi Maha Mengetahui. ${ }^{9}$

Al-Qur'an Q.S. al-Taubah (9); 60, menerangkan orang yang berhak menerima zakat:

Terjemahnya;

${ }^{7}$ Dewan Redaksi Ensiklopedi Islam, Ensiklopedi Islam. Cet. 3 (Jakarta: Ictiar Baru Van Hoeve, 1994), h. 224. bandingkan dengan Cyril Glasse, Ensiklopedi Islam (ringkas) Cyril Glasse, Cet. 3 (Jakarta; PT. Raja Grafindo Persada, 2002), h. 445. dan lihat; bandingkan dengan Majma' Lughah alArabiyah, Mu'jam al-wasit, juz I (Mesir; Dar al-Ma'arif, 1972), h. 396

${ }^{8}$ Fachruddin , Ensiklopedia Al-Qur'an. Buku 2 (Jakarta, PT. Rineka Cipta 1992), h. 619

9 Al-Qur'an dan Terjemahan. [658] Maksudnya: zakat itu membersihkan mereka dari kekikiran dan cinta yang berlebih-lebihan kepada harta benda. [659] Maksudnya: zakat itu menyuburkan sifatsifat kebaikan dalam hati mereka dan memperkembangkan harta benda mereka 
Sesungguhnya zakat-zakat itu, hanyalah untuk orang-orang fakir, orang-orang miskin, pengurus-pengurus zakat, para mu'allaf yang dibujuk hatinya, untuk (memerdekakan) budak, orang-orang yang berhutang, untuk jalan Allah dan untuk mereka yuang sedang dalam perjalanan, sebagai suatu ketetapan yang diwajibkan Allah, dan Allah Maha mengetahui lagi Maha Bijaksana. ${ }^{10}$

Dijelaskan juga dalam Hadist yang diriwayatkan oleh Bukhari:

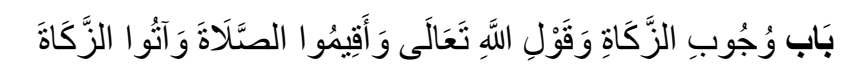

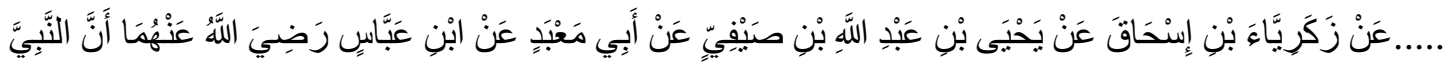

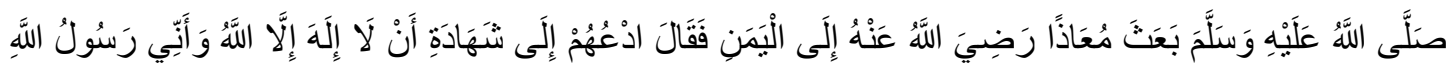

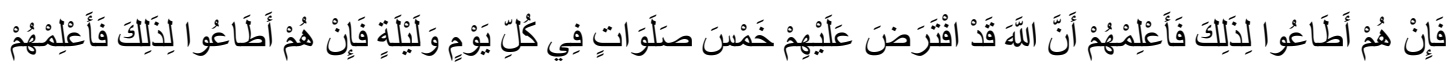

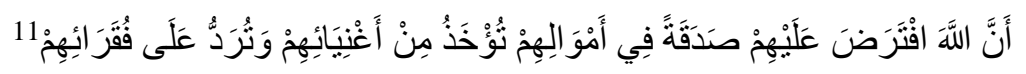

Artinya:

Diriwayatkan dari Ibn 'Abbas r.a, Nabi Muhammad Saw., mengutus Muradz r.a., ke Yaman dan berpesan kepadanya, "Ajaklah mereka untuk bersaksi bahwa tiada Tuhan selain Allah dan Aku (Muhammad) adalah utusan Allah, dan Apabilah mereka mengikuti ajakanmu, beri tahu mereka bahwa Allah memerintahkan mereka mengerjakan shalat lima waktu dalam sehari semalam, dan jika mereka menaatimu mengerjakan perintah itu, beritahu mereka bahwa Allah memerintahkan mereka membanyar sedekah (Zakat) dari kekayaan mereka yang diambil dari orang-orang kaya di antara mereka dan berikan kepada orang-orang miskin di antara mereka. (HR; Bukhari, Nomor 1316, Kitab. Zakat)

\section{SASARAN PELAKSANAAN ZAKAT}

Islam bukanlah agama yang membiar-kan segala permasalahan ini hadir tanpa batas. Namun Islam pun tumbuh dengan banyak kepedulian positif terhadap realitas permasalahan, seperti fenomena perekono-mian. Zakat yang merupakan rukun Islam

\footnotetext{
${ }^{10} \mathrm{Al}$-Qur'an dan Terjemahan

${ }^{11}$ Shahih Bukhari, Juz VI (Darul Fikr), h. 166
} 
ketiga yang dianggap mempunyai peran yang signifikan dalam mengatasi berbagai permasalahan ekonomi. permasalahan ter-sebut yaitu: 1. Pengangguran, 2. Kemiskinan, 3. Beban krisis dan hutang piutang, 4. Perekonomian buruk, 5. Penimbunan harta. $^{12}$

Rendahnya nilai perilaku ekonomi baik personal lebih-lebih moral dan tak adanya pengawasan akan membawa kerusakan ekonomi masyarakat. Sebagaimana dalam QS.Al-Taubah; (9): 103

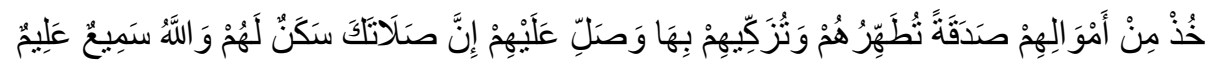

Terjemahnya;

Ambillah zakat dari sebagian harta mereka, dengan zakat itu kamu membersihkan [658] dan mensuci-kan [659] mereka dan mendoalah untuk mereka. Sesungguhnya doa kamu itu (menjadi) ketenteraman jiwa bagi mereka. dan Allah Maha mendengar lagi Maha Mengetahui. ${ }^{13}$

Ayat ini tegas menyatakan perintah kepada Rasul selain sebagai Nabi ia juga bertugas melaksanakan hukum-hukum Allah dalam masyarakat untuk mewujudkan kesejahteraan dan kesentosaan rakyat yang juga merupakan tujuan ekonomi yang di kehendaki Al-Qur'an. Tugas-tugas demikian dilaksanakan oleh khalifah sebagai kepala pemerintahan. Dari sini dapat dipahami bahwa pemerintah adalah juga pelaku ekonomi, bahkan yang lebih kuat karena di tangannyalah terletak penentuan kebijakan ekonomi.

Salah satu kebijakan ekonomi yang dapat dipahami dari ayat di atas adalah perintah kepada nabi agar beliau berupaya memberi ketentraman kepada masyarakat. Ini berarti pemerintah harus aktif mewujud-kan dan memelihara ketentraman masya-

${ }^{12}$ Yusuf Qaradhawi, Spektrum Zakat Dalam Membangun Ekonomi Rakyat .Terjemahan dari judul Dauru Al-Zakat, fi'Iiaaj al-Musykilaat al-Iqtisshaadiyah (Jakarta; Zikrul Hakim, 2005), h. 2

${ }^{13}$ Al-Qur'an dan Terjemahan. [658] Maksudnya: zakat itu membersihkan mereka dari kekikiran dan cinta yang berlebih-lebihan kepada harta benda. [659] Maksudnya: zakat itu menyuburkan sifatsifat kebaikan dalam hati mereka dan memperkembangkan harta benda mereka 
rakat. Ini dapat terwujud jika dalam masya-rakat terdapat faktor-faktor dan sarana ekonomi yang memadai dan kondisi sosial ekonomi dan keamanan yang mapan. ${ }^{14}$

Zakat mencakup semua pembayaran wajib di jalan Allah, dan dikenakan pada berbagai jenis aset, beberapa di antaranya mungkin jatuh ke dalam kategori modal. Dari sudut pandang sistem keuangan, penting untuk dicatat bahwa semua saham keuangan dan modal kerja tunduk pada kewajiban-kewajiban tersebut. ${ }^{15}$

Zakat adalah musuh yang dikenal tidak kompromi bagi pekerjaan menimbun, ia mencegah kecenderungan untuk menimbun sumber daya, dan uang tunai yang tidak digunakan. Ia juga memberikan dorongan kuat untuk menginvestasi persediaan yang tidak terpakai. Dorongan ini memperoleh kekuatan dari kenyataan bahwa Islam memperkenankan laba dan mitra usaha, dengan berbagi laba maupun kerugian. ${ }^{16}$

Zakat sebagai Alat bukan tujuan, sehingga mengandung metode dan fleksi-bilitas yang tinggi. Sasaran yang dikehen daki adalah kemaslahatan dan kesejahteraan umat. Itulah sebabnya adanya ukuran mini-mal yang wajib kena zakat. Disini pula perbedaannya dengan sistem tarif dan pajak modern, dimana lebih banyak berorentasi pada bentuk progresif. Zakat mendorong motovasi dan kreasi masyarakat dalam pemilikan dan penggunaan harta kekayaan. Olehnya itu zakat harus ditegak-kan dengan dukungan yang terpadu dari masyarakat dan pemerintah. Tergambar pemerintah yang arif dan bijaksana akan memahami peran zakat, yang mampu menyelesaikan masalah kemis-kinan dan kefakiran serta perilaku negatif yang dapat ditimbulkan ${ }^{17}$

Zakat mewujudkan kemandirian sosial tidak sama dengan suatu kewajiban membayar pajak bagi warga negara. Ini meru-pakan kewajiban agama secara mutlak dari Tuhan Yang Maha Pencipta kepada umat manusia sebagai amanah untuk menge-

\footnotetext{
${ }^{14}$ Abd Muin Salim, Ekonomi dalam Perspektif Al-Qur'an, Sebuah Pengantar Pengenalan Dasar Ekonomi Islam, (Ujung Pandang; Yayasan Kesejahteraan Islam YAKIS Syariah, 1994), h. 9

${ }^{15}$ M. Fahim Khan, Essays in Islamic Economics, Islamic Economics Series-19 (United Kingdom; Islamic Funddation, 1995), h. 79

${ }^{16}$ M. Abdul Mannan, Teori dan Praktek Ekonomi Islam (Yogyakarta; PT.Dana Bhakti Prima Yasa, 1997), h. 167

${ }^{17}$ Lihat,- Abdurahman A. Basalamah, Ekonomi Bulan sabit, h. 31-33
} 
luarkan kekayaan yang telah Dia anugerah-kan sebagai bentuk keimanan, ditunaikan kepada orang yang kurang beruntung. Ini merupakan salah satu bentuk ketentuan peribadatan yang dalam Islam tidak hanya meliputi shalat, puasa dan haji; tetapi juga mencakup pemenuhan kewajiban kepada orang lain. Salah satu cara untuk mengerjakan kewajiban itu, yang di tuntut Islam dari kaum Muslim, adalah melalui intitusi zakat, yang merupakan bagian yang tidak terpisah dari keimanan. Zakat adalah tanda yang jelas dan tegas dari kehendak Tuhan untuk menjamin bahwa tidak seorang pun menderita kekurangan sarana untuk meme-nuhi kebutuhan pokok akan barang dan jasa. $^{18}$

Zakat merupakan harta yang wajib disisihkan oleh seorang muslim atau badan yang dimiliki oleh orang muslim sesuai ketentuan agama untuk diberikan kepada yang berhak menerimanya. Konsep zakat sesungguhnya mengandung tiga dimensi penting kehidupan manusia; Pertama; dimensi spritual, yaitu untuk membersihkan diri , mensucikan jiwa, dan menentramkan hati (QS. At-Taubah; 103), demensi spritual zakat menunjukkan bahwa zakat merupakan unsur penting untuk membuktikan keimanan dan ketakwaan manusia kepada Sang Khalik. Kedua, dimensi sosial. Zakat merupakan realisasi nyata dari solidaritas sosial masyarakat yang mampu kepada masyarakat yang kurang mampu, Islam mengajarkan keseimbangan tatanan sosial melalui Zakat. Ketiga, dimensi pemberdaya-an masyarakat. Zakat tidak dimaksud untuk menciptakan kondisi ketergantungan kepada kelompok miskin kepada kelompok kaya, melainkan untuk menimbulkan kemandirian masyarakat miskin. Pemanfaatan zakat untuk tujuan yang produktif mestinya lebih diproritaskan dari pada pemanfaatan yang cenderung konsumtif. ${ }^{19}$

\footnotetext{
${ }^{18}$ M. Umer Chapra, Islam dan Tantangan Ekonomi; Islam Ekonomi Konterporer (Surabaya; Risalah Gusti, 1999), h.292-293

${ }^{19}$ URLartikel; http:/www.penulislepas. com
} 
Adapun hikmah zakat banyak sekali, baik yang mengeluarkan, penerima maupun bagi masyarakat pada umumnya antaranya: ${ }^{20}$

1. Bagi yang mengeluarkan zakat

a. Sebagai rasa syukur kepada Allah Swt., atas segalah nikmat yang dilimpahkan kepadanya.

b. Membersihkan diri dari sifat kikir, serta mendidik diri agar bersifat mulia dan pemurah dengan mem-biasakan diri membayarkan amanah kepada orang yang berhak

c. Membersihkan harta dari kemung-kinan tercampur dengan harta haram

2. Bagi Penerima zakat

a. Merupakan upaya untuk menolong dan membantu dalam rangka mengatasi kesulitan dan kemis-kinan

b. Dapat memperteguh dan memupuk iman orang-orang mua'allaf

3. Bagi masyarakat

a. Mendidik jiwa manusia suka ber-korban dan membersihkan jiwa dari sifat-sifat kikir dan bakhil

b. Zakat mengandung arti rasa per-samaan yang memikirkan nasib manu-sia dalam suasana persaudaraan

c. Zakat memberikan arti bahwa manu-sia itu bukan hidup untuk dirinya sendiri.

d. Zakat dapat menjaga timbulnya rasa iri, dengki dan menghilangkan jurang pemisah antara si miskin dan si kaya

e. Zakat bersifat sosialistis, karena me-ringankan beban orang yang sedang kesusahan dan meratakan nikmat Allah yang diberikan kepada manusia.

Dalam al-Qur'an terdapat 82 kali kata harta (al-Maal). Jika dilihat dari bentuk katanya sebagian besar dalam bentuk jamak. Hal ini menunjukkan bahwa harta benda itu merupakan milik bersama (public goods), meskipun ia dimiliki oleh perorangan. Dengan arti lain harta itu berfungsi sosial. Fungsi sosial harta tidak semata-mata dalam

${ }^{20}$ M. Abdul Mujieb, dkk. Kamus Istilah Fiqih (Jakarta; PT Pustaka Firdaus, 1994), h. 428 
peranannya sebagai barang konsumtif yang dibagi-bagikan dan dibutuhkan oleh masya-rakat, tetapi lebih berperan kepada fungsi ekonomik edukatif, ${ }^{21}$ yaitu :

1. Sirkulatif distributive dalam sistem ekonomi masyarakat untuk mecegah terkonsentrasinya modal atau harta ditangan para aghnia, sebagaimana yang telah dijelaskan dalam al-Qur'an surat al-hasyr ayat 7 tadi. Harta itu disalurkan pada bidang-bidang produktif, bekerja sama dengan masyarakat golongan eko-nomi lemah yang membutuhkan peker-jaan sebagai sumber kehidupan.

2. Bahwa sifat harta itu adalah berkem-bang, dan nilainya berkembang. Nilai edukatif harta bertujuan untuk mendidik manusia menjauhi sifat bakhil dan tamak yang bertentangan dengan tujuan Tuhan memberikan harta kepada seseorang, sebagaimana ditegaskan dalam al-Qur'an surat Ali Imran ayat 180 : “ sekali-kali janganlah orang-orang yang bakhil dengan harta yang Allah berikan kepada mereka dari karunia-Nya menyangka, bahwa kebakhilan itu baik bagi mereka. Sebenarnya kebakhilan itu buruk bagi mereka..."

3. Efektif, yaitu harta sebagai modal harus berperan dalam berbagai lapangan produktif yang akan tersalur dalam berbagai lapangan usaha secara distributif yang dapat menampung dan menjalankan produktifitas dan efektifitas ekonomi. Dan menghindari terjadinya penimbunan harta yang sangat merugika orang banyak dan pemilik harta itu sendiri, sebagaimana firman Allah dalam surat at-taubah ayat 9 :" Orang-orang yang menimbun emas dan perak, dan tidak menginfakan hartanya dijalan Allah, maka beritahukan kepada mereka bahwa diakhirat nanti mereka ditimpa-kan azab yang pedih."

Zakat memainkan dua fungsi penting. Pertama, mensucikan hati atau jiwa si pemberi dari kejahatan-kejahatan sifat kikir dan sebagai gantinya mendorong pemberian sedekah dan mengeluarkan barang atau harta yang baik. Kedua, akan mengantarkan suatu komunitas menuju perkembangan yang sehat. Zakat dapat

\footnotetext{
${ }^{21}$ Abdurrahman Qadir, Zakat "Dalam Dimensi Mahdhah dan Sosial” (PT. Raja Grafindo Persada, Jakarta,cet ke 2, th 2001, Cit), hal 6-7
} 
mencegah segala pengaruh yang bersifat penghalang dan mendorong orang untuk ikut membantu mencapai kemajuan dalam bidang ekonomi ${ }^{22}$ dan zakat adalah jaminan sosial. $^{23}$

Pada saat ini telah ada berbagai peraturan yang mengatur tentang penge-lolaan zakat, yaitu;

1. Undang-undang Nomor 38 Tahun 1999 tentang Pengelolaan Zakat

2. Undang-Undang Nomor 17 Tahun 2000 tentang Perubahan Ketiga atas UU No. 7 Tahun 1983 Tentang Pajak Penghasilan

3. Keputusan Menteri Agama Nomor 581 Tahun 1999 tentang Pelaksanaan UU No. 38 Tahun 1999 tentang Pengelolaan zakat.

4. Keputusan Dirjen Bimas Islam dan Urusan Haji Nomor D/291 tentang Pedoman Teknis Pengelolaan Zakat

Tentunya dengan adanya aturan-aturan tersebut, pengelolah zakat yang di lakukan oleh organisasi pengelolah zakat, baik Badan Amil Zakat (BAZ) maupun Lembaga Amil Zakat (LAZ), diharapkan bisa lebih baik.

\section{TAWARAN KONSEP}

Pemanfaatan dan pendayagunaan dana zakat dapat digolongkan menjadi empat bagian sebagai berikut :

1. Konsumtif Tradisional. Yaitu zakat digunakan dan dimanfaatkan langsung oleh mustahik seperti zakat fitrah yang diberikan langsung kepada fakir miskin untuk memenuhi kebutuhan sehari-hari atau zakat harta benda yang diberikan untuk korban bencana alam.

2. konsumtif Kreatif. Yaitu zakat diwujud-kan dalam bentuk lain dari barangnya semula seperti diwujudkan dalam bentuk alat-alat sekolah, beasiswa.

\footnotetext{
${ }^{22}$ Afzalurrahman, Muhammad sebagai Seorang Pedagang "Muhammad as A Trader" (Yayasan Swarna Bhumy; Jakarta, 2000), h. 14

23 Yusuf Qaradhawi, Hukum Zakat "studi Komprehensip Mengenai status dan Filsafat Zakat Berdasarkan Qur’an dan Hadis ( Bogor; Pustaka Litera Antar Nusa, 2004) h.878
} 
3. produktif Tradisional. Yaitu zakat yang diberikan dalam bentuk produktif seperti kambing, sapi, mesin jahit dan sejenisnya. Pemberian dalam bentuk ini dapat mendorong orang menciptakan suatu usaha atau memberikan suatu lapangan pekerjaan baru bagi fakir miskin.

4. Produktif Kreatif. Yaitu pendayaguna-an zakat diwujudkan dalam bentuk modal baik untuk membangun proyek sosial maupun menambah modal seorang pedagang atau usaha kecil.

Model terakhir ini telah dicontohkan oleh nabi Muhammad SAW. Beliau pernah memberikan zakat kepada seorang fakir sebanayak 2 dirham untuk makan dan satu dirham untuk dibelikan sebuah kapak sebagai alat untuk bekerja agar hidupnya tidak menggantungkan kepada orang lain. ${ }^{24}$

\section{IMPLEMENTASI}

Pencapaian hasil yang maksimal, efektif, dan efesien serta tercapainya tujuan dan sasaran zakat, maka pendayagunaannya haruslah produktif. Tentang model dan mekanisme pendayagunaan zakat produktif dimaksud disusun sedemikian rupa oleh lembaga pengelola yang membantu permodalan dalam berbagai bentuk kegiatan ekonomi masyarakat dan pengembangan usaha-usaha golongan ekonomi lemah, khususnya fakir miskin yang umumnya mereka menganggur atau tidak berusaha secara optimal karena ketiadaan modal.

Terhadap mereka ini, diberikan zakat dalam bentuk pinjaman modal usaha berupa pinjaman kebajikan (qardhul hasan). Se-terusnya dana zakat yang terhimpun, dan dana yang dikembalikan oleh peminjam diatas digulirkan pula kepada mustahik lain, dan seterusnya sampai seluruh golongan fakir miskin bisa mandiri dalam membangun kehidupan ekonominya. Jika dalam masa pengembalian pinjaman qardhul hasan diatas terjadi force majure atau kehilangan diluar kemampuannya maka si peminjam dibebas-kan dari hutangnya. Model zakat qardhul hasan ini hampir sama

\footnotetext{
${ }^{24}$ Syeikhul hadi Pramono, Pendayagunaan zakat dalam rangka pembangunan nasional, Pustaka firdaus, thn 1995, hal 52
} 
dengan pinjaman modal ventura program pengentasan kemiskinan. Model pemberian zakat konvensional dengan pola garis konsumtif seperti yang diterapkan selama ini hanya diberikan kepada fakir miskin yang betul-betul tidak mempunyai potensi produktif, seperti karena usia lanjut, cacat mental dan fisik.terhadap mustahik tipe ini lembaga pengelola mempunyai wewenang unutk menetapkan cara bagaimana menuntaskan kemiskinan mereka dengan harta zakat itu. ${ }^{25}$

Afzalurrahman mengungkapkan cara terbaik untuk membatu mereka melalui dana zakat adalah:

1. Membagung lembaga nasional dan tempat-tempat kesejahteraan masyara-kat (tempat tinggal orang miskin dan anak yatim, lembaga-lembaga pendi-dikan, rumah sakit geratis

2. Bantuan modal bagi yang menganggur

3. Petani miskin diberi bibit, pupuk, alat pertanian dan dibayarkan utang-utang mereka yang diperuntukkan untuk membiayai pertanian

4. Orang miskin yang mempunyai keahlian diberikan peralatan dan modal (industri (kecil) $)^{26}$

Ada tiga tujuan utama zakat ditinjau dari beberapa aspek yang dikemukan oleh al-Qardhawi yaitu :

1. Pihak para wajib zakat atau muzakki

Tujuan zakat dari muzakki adalah untuk mensucikan dari sifat kikir, bakhil, rakus dan egoistis, melatih jiwa untuk bersikap terpuji seperti bersyukur atas nikmat Allah, mengobati batin dari sikap berlebihan mencintai harta sehingga dapat di perbudak oleh harta itu sendiri, menum-buhkan sikap rasa kasih saying antar sesame, membersihkan nilai harta itu sendiri dari unsur noda dan cacat serta melatih diri agar menjadi pemurah dan berakhlak yang mulia.

2. Pihak penerima zakat atau mustahik.

\footnotetext{
${ }^{25}$ Abdurrahman qadir, Op. Cit, hal 171-172

${ }^{26}$ Afzalurrahman, Op. Cit, h. 185
} 
Bagi mereka si penerima zakat dapat memenuhi kebutuhan hidupnya, terutama kebutuhan primer sehari-hari, tersucikannya hati mereka dari rasa dengki dan kebencian yang menyelimuti hati mereka melihat orang yang kaya bakhil. Selanjutnya akan tumbuh dalam jiwa mereka rasa simpatik, hormat, serta rasa tanggung jawab untuk itu, meng-amankan dan mendoakan keselamatan dan pengembangan harta orang-orang kaya.

\section{Kepentingan masyarakat (sosial)}

Ditinjau dari kepentingan kehidupan masyarakat adalah bahwa zakat bernilai ekonomi, merealisasikan fungsi harta sebagai alat perjuangan menegakkan agama Allah, dan mewujudkan keadilan sosial ekonomi masyarakat pada umumnya. ${ }^{27}$

Kepemimpinan khalifah Umar bin Abdil Aziz yang telah merubah keadaan yang sebelum kekhalifaannya begitu jauh kemelaratan rakyat dan penderitaan umat. Pada masa pemerintahannya khalifah Umar bin Abdil Azis merubah keadaan kearah perubahan yang meng-gembirakan, seolah-olah dewi kemakmuran itu datang berlari lari mengejar rakyat untuk menghadiahkan kebahagiaan, kesejahteraan dan kesenangan hidup kepada mereka setelah menderita berpuluh-puluh tahun di bawah pemerintah-an rezim lama. Dapatlah dikatakan bahwa, rakyat di bawah pemerintahan Umar bin Abdil Aziz seolah-olah hidup di dalam "Surga dunia" layaknya. Demikian makmur-nya rakyat ketika itu sehingga susah mencari orang yang fakir dan miskin untuk menerima zakat. Rata-rata manusia hidup dalam kemakmuran yang merata dan adil. Kalau bagi kita kemakmuran yang merata itu baru merupakan impian dan semboyang dalam janjijanji para pemimpin, maka pada zaman Khalifah Umar bin Abdil Aziz, negeri yang banyak padang pasirnya seolah-olah disulap beliau menjadi taman yang hijau yang indah permai di mana memancar-kan kebahagiaan dan kenikmatan hidup untuk seluruh rakyat; selaku karunia Tuhan terhadap suatu negara yang diasuh dan dirawat dengan segala keikhlasan dan ketekunan.

\footnotetext{
${ }^{27}$ Yususf Qardhawi, Fiqh al-Zakah, Muassasah ar-Risalah (Beirut, 1991), hal 108-109
} 
Umar bin Abdil Aziz menduduki singgasana Khalifah hanya selama dua setegah tahun. Tetapi dalam masa yang singkat itu betul-betul telah berhasil membuat rakyatnya menjadi kaya dan makmur, sehingga orang yang ingin mengeluarkan zakat terpaksa mondar-mandir kesana-sini mencari orang yang patut menerimanya, tetapi tidak juga menemukan yang berhak menerima zakat, sampai ketika Umar bin Abdil Aziz mengirim utusan ke Afrika Utara untuk membagi-bagikan zakat penduduk di sana, akan tetapi tidak men-dapatkan seorang fakir miskin pun yang berhak atas zakat. Dalam artian bahwa Khalifah Umar betul-betul telah memberik-an kekayaan kepada rakyatnya. $^{28}$

\section{DAFTAR PUSTAKA}

Al-Qur'an dan Terjemahan

Abdurahman A. Basalamah, Ekonomi Bulan sabit, Gerakan Pembagunan Dalam Konsep Islam. Ujung Pandang; PT. Umitoha Ukhuwah Grafika, 1996

Abdurrahman Qadir , Zakat "Dalam Dimensi Mahdhah dan Sosial”. PT. Raja Grafindo Persada, Jakarta,cet ke 2, th 2001, Cit

Afzalurrahman, Muhammad sebagai Seorang Pedagang "Muhammad as A Trader". Yayasan Swarna Bhumy; Jakarta, 2000

Cyril Glasse, Ensiklopedi Islam (ringkas) Cyril Glasse, Cet. 3. Jakarta; PT. Raja Grafindo Persada, 2002

Dewan Redaksi Ensiklopedi Islam, Ensiklopedi Islam. Cet. 3. Jakarta: Ictiar Baru Van Hoeve, 1994

Fachruddin, Ensiklopedia Al-Qur'an. Buku 2. Jakarta, PT. Rineka Cipta 1992

Firdaus A.N, Kepemimpinan Khalifah Umar Bin Abdil Aziz. Cet. 5. Jakarta; CV. Pedoman Ilmu Jaya, 1996

Majma' Lughah al-Arabiyah, Mu'jam al-wasit, juz I. Mesir; Dar al-Ma'arif, 1972

Shahih Bukhari, Juz VI Darul Fikr

Syeikhul hadi Pramono, Pendayagunaan zakat dalam rangka pembangunan nasional, Pustaka firdaus, 1995

${ }^{28}$ K.H. Firdaus A.N, Kepemimpinan Khalifah Umar Bin Abdil Aziz. Cet. 5 (Jakarta; CV. Pedoman Ilmu Jaya, 1996), h. 184 
Taqyuddin An-Nabhani. Membangun Sistem Ekonomi Alternatif Perspektif Islam. Surabaya; Risala Gusti, 1996

Yusuf Qaradhawi, Spektrum Zakat Dalam Membangun Ekonomi Rakyat .Terjemahan dari judul Dauru Al-Zakat, fi'Iiaaj al-Musykilaat al-Iqtisshaadiyah. Jakarta; Zikrul Hakim, 2005

Yusuf Qaradhawi. Hukum Zakat "studi Komprehensip Mengenai status dan Filsafat Zakat Berdasarkan Qur'an dan Hadis. Bogor; Pustaka Litera Antar Nusa, 2004

Yususf Qardhawi, Fiqh al-Zakah, Muassasah ar-Risalah, Beirut, 1999 